\title{
Associations of dietary dark-green and deep-yellow vegetables and fruits with cervical intraepithelial neoplasia: modification by smoking
}

\author{
Luciana Y. Tomita ${ }^{1}$, Cecília M. Roteli-Martins ${ }^{2}$, Luisa L. Villa ${ }^{3}$, Eduardo L. Franco ${ }^{4}$, Marly A. Cardoso ${ }^{1 *}$ \\ and for the BRINCA Study Team $\dagger$ \\ ${ }^{1}$ Department of Nutrition, School of Public Health, University of São Paulo (USP), Avenida Dr Arnaldo, 715, 01246-904 \\ São Paulo, SP, Brazil \\ ${ }^{2}$ Hospital Leonor Mendes de Barros, Avenida Celso Garcia, 2477, 03015-000 São Paulo, SP, Brazil \\ ${ }^{3}$ Ludwig Institute for Cancer Research, Rua João Julião, 245, 01323-903 São Paulo, SP, Brazil \\ ${ }^{4}$ Division of Cancer Epidemiology, McGill University, 546 Pine Avenue West, Montreal, QC, Canada H2W 1S6
}

(Received 31 March 2010 - Revised 18 September 2010 - Accepted 27 September 2010 - First published online 24 November 2010)

\begin{abstract}
Smoking has been positively and fruit and vegetable intake has been negatively associated with cervical cancer, the second most common cancer among women worldwide. However, a lower consumption of fruits and reduced serum carotenoids have been observed among smokers. It is not known whether the smoking effect on the risk of cervical neoplasia is modified by a low intake of fruits and vegetables. The present study examined the combined effects of tobacco smoking and diet using a validated FFQ and serum carotenoid and tocopherol levels on cervical intraepithelial neoplasia grade 3 (CIN3) risk in a hospital-based case-control study conducted in São Paulo, Brazil, between 2003 and 2005. The sample comprised 231 incident, histologically confirmed cases of CIN3 and 453 controls. A low intake $(\leq 39 \mathrm{~g})$ of dark-green and deep-yellow vegetables and fruits without tobacco smoking had a lesser effect on CIN3 (OR 1.14; $95 \%$ CI $0.49,2.65)$ than among smokers with higher intake ( $\geq 40 \mathrm{~g}$; OR 1.83; $95 \%$ CI $0.73,4.62)$ after adjusting for confounders. The OR for the joint exposure of tobacco smoking and low intake of vegetables and fruits was greater $(3 \cdot 86 ; 95 \%$ CI $1.74,8.57 ; P$ for trend $<0.001)$ compared with non-smokers with higher intake after adjusting for confounding variables and human papillomavirus status. Similar results were observed for total fruit, serum total carotene (including $\beta-, \alpha$ - and $\gamma$-carotene) and tocopherols. These findings suggest that the effect of nutritional factors on CIN3 is modified by smoking.
\end{abstract}

\section{Key words: Uterine cervical neoplasms: Smoking: Diet: Interaction}

Cervical cancer is the second most common cancer among women worldwide, with the highest rates occurring in developing countries ${ }^{(1)}$. The high incidence in these regions is attributed to inadequate screening and other factors strongly correlated with socio-economic and demographic characteristics ${ }^{(2,3)}$. Human papillomavirus (HPV) infection is considered a necessary but not sufficient cause of cervical cancer, since most women infected with HPV do not develop cervical cancer, while many cofactors such as tobacco smoking, oral contraceptive use and high parity play ancillary roles in the disease process ${ }^{(4-8)}$. Tobacco smoking has been associated with the early stages of carcinogenesis, from the acquisition of HPV infection to cervical cancer, increasing the risk twofold relative to non-smokers ${ }^{(7-9)}$. The impaired immunological response and increased free radicals produced by cigarette smoking provide the biological plausibility for a link between tobacco and cervical cancer ${ }^{(10,11)}$.

Abbreviations: BRINCA, Brazilian Investigation into Nutrition and Cervical Cancer Prevention; CIN3, cervical intraepithelial neoplasia grade 3; HPV, human papillomavirus; ROS, reactive oxygen species.

*Corresponding author: Dr M. A. Cardoso, email marlyac@usp.br

† The BRINCA study team includes: Marly A. Cardoso, Luciana Y. Tomita, Lana C. Almeida (Department of Nutrition, School of Public Health, University of São Paulo, Brazil), Adhemar Longatto Filho, Maria da Gloria Mattosinho de Castro Ferraz, Maria Lucia Utagawa, Luciana S. Aguiar (Pathology Department, Adolfo Lutz Institute, Brazil), Cecília Maria Roteli-Martins (Hospital Leonor Mendes de Barros, São Paulo, Brazil), Ronaldo Lucio Rangel Costa (Instituto Brasileiro de Controle do Câncer, São Paulo, Brazil), Marcos Desidério Ricci (Hospital Perola Byington, São Paulo, Brazil), Venâncio Avancini Ferreira Alves (Department of Pathology, School of Medicine, University of São Paulo, Brazil), Vânia D'Almeida (Health Science Department, Federal University of São Paulo, Brazil), Márcia A. Sperança, Anete M. Francisco-Bagnariolli (School of Medicine of Marília, Brazil), Luisa Lina Villa, Maria Cecília Costa, Maria Antonieta Avilla Andreoli, João Simão Pereira Sobrinho, José Carlos Mann Prado (Ludwig Institute for Cancer Research, São Paulo, Brazil), Eduardo L. Franco (Division of Cancer Epidemiology, McGill University, Canada). 
Nutritional factors, mainly antioxidants such as carotenoids and tocopherols, have been associated with the cervical carcinogenic process: from the clearance of HPV infection, persistence of the virus causing the early stages of carcinogenesis to the late stages of cervical neoplasia and invasive cancer through immunological deprivation ${ }^{(12-22)}$. A diet rich in vegetables and fruits has been recommended for the prevention of cancer due to their antioxidant properties, which reduce the toxic effects of reactive oxygen species (ROS) and possible enhancement of the immune response ${ }^{(23,24)}$. ROS can affect fluidity and integrity of the membrane of immunological cells causing changes in the distribution and function of cellular receptors $^{(24)}$. A slightly lower consumption of carotenoids and vitamin C, particularly from fruits, has been observed among smokers compared with among non-smokers ${ }^{(25-29)}$. Lower serum concentrations of antioxidants, especially carotenoids, have been observed among smokers independently of dietary intake, which further increases the effect of a low intake of fruits ${ }^{(25-30)}$. Thus, it is unknown whether the smoking effect on the risk of cervical neoplasia is modified by a low intake of fruits and vegetables.

The present study aimed to investigate the joint effect of fruit and vegetable intake, serum concentrations of carotenoids and tocopherols and smoking on the risk of cervical intraepithelial neoplasia grade 3 (CIN3, the lesion grade accepted as a cervical cancer precursor) in a hospital-based case-control study.

\section{Subjects and methods}

\section{Study setting}

Participants in the present study were selected from the Brazilian Investigation into Nutrition and Cervical Cancer Prevention (BRINCA) study, a hospital-based case-control study designed to investigate the relationship between diet and cervical cancer in São Paulo, Brazil. The present study was conducted according to the guidelines laid down in the Declaration of Helsinki, and all procedures involving human subjects were approved by the São Paulo University School of Public Health Ethics Committee. Written informed consent was obtained from all subjects. The BRINCA study included women attending two major hospitals (Instituto Brasileiro de Controle do Câncer and Hospital Perola Byington) in São Paulo, Brazil, for cervical cytological screening. We prospectively recruited newly diagnosed cases of CIN and invasive cancer. Eligible women were residents of São Paulo aged 21-65 years and had no prior hysterectomy, no previous treatment for CIN and no cancer history. Women who were positive for HIV or who had been pregnant or breastfeeding within 6 months of enrolment were ineligible.

Cases included women with a histological diagnosis of CIN grades 1 (CIN1), 2 (CIN2) or 3 (CIN3) or invasive adenocarcinoma, adenosquamous or squamous cell carcinoma of the cervix, reviewed by two pathologists. During the same period, control women were selected from among those attending screening in the same clinics where cases were diagnosed. To be eligible, control women had to have a cytological diagnosis within normal limits, in addition to meeting the above-mentioned criteria for cases.

Sampling strategies, participation rates and initial results from the BRINCA study have been reported elsewhere ${ }^{(22,30)}$. A total of 1729 women were contacted between 2003 and 2005. Among these women, fiftythree $(3.1 \%)$ refused participation (thirty-four potential cases and nineteen potential controls) and 1676 were interviewed. Among them, 1394 (83.2\%) completed the study protocol. Among those enrolled, 1179 women were eligible for the present study. Overall, 121 participants were excluded due to incomplete data, and the final study groups included 453 controls and four case groups (140 CIN1, 126 CIN2, 231 CIN3 and 108 cervical cancer cases). The present analysis included 453 controls and 231 women diagnosed with CIN3, an acceptable precancerous cervical lesion, due to considerable sample size for comparisons. We did not include invasive cancer cases because of the possible effects of the disease process on the nutritional measurements.

\section{Data collection}

Participants underwent a personal interview by trained dietitians blinded to the group assignment. A standardised questionnaire was used to elicit information on socioeconomic and demographic characteristics, physical activity (including both occupational and leisure activities, expressed in metabolic equivalent tasks in $\mathrm{h} /$ week), tobacco use (current smoker, former smoker or nonsmoker; individuals who had quit smoking at least 1 year before the interview were considered former smokers), alcohol consumption, reproductive and sexual histories and other risk factors for cervical neoplasia. Self-reported race/ethnicity was classified as white and non-white (black women and mulatto).

BMI was expressed as $\mathrm{kg} / \mathrm{m}^{2}$ and calculated based on weight and height measurements with subjects wearing light clothes and no shoes, according to standard protocols and cut-offs proposed by the $\mathrm{WHO}^{(31)}$.

Food consumption was assessed using a validated $\mathrm{FFQ}^{(32)}$ and adapted to epidemiological studies on diet and chronic diseases in São Paulo ${ }^{(33)}$. Briefly, energyadjusted, attenuation-corrected Pearson validity correlations between FFQ and three dietary recalls ranged mostly from 0.40 to $0 \cdot 75$. Bland-Altman plots indicated that the FFQ is accurate in assessing nutrient intake at a group level, and a small proportion of grossly misclassified nutrient intakes was observed ${ }^{(34)}$. Intake of fruits and vegetables assessed by the FFQ was a good predictor of serum total carotene whose intakes contributed to about $5 \%$ of 
the serum total carotene concentration, after adjusting for confounding variables ${ }^{(30)}$.

Women were asked about their usual frequency of consumption of seventy-six food items and their portion sizes, an open-ended food section, and vitamin and mineral supplements during the previous year. A validation study with good accuracy for the FFQ was also observed in a random sub-sample of ninety-six cases and controls from the BRINCA study, using three $24 \mathrm{~h}$ dietary recalls obtained during a year, as reported previously ${ }^{(30)}$. Nutrient and food groups were analysed using the DietSys software version 4.01 (National Cancer Institute, Bethesda, MD, USA) ${ }^{(35)}$. The nutrient database was based primarily on the US Department of Agriculture publications supplied by DietSys and supplemented by the Brazilian Standard Food Composition table. Questionnaires were excluded from further analysis if energy intake was implausible $<2929 \mathrm{~kJ} / \mathrm{d}(700 \mathrm{kcal} / \mathrm{d})$ or $>25104 \mathrm{~kJ} / \mathrm{d}(6000 \mathrm{kcal} / \mathrm{d})$, corresponding to the percentiles $<2.5$ or $>97.5$, respectively. In the present study, two controls and one woman with diagnosis of CIN3 reported implausible values of dietary intake. For the present study, we investigated five food groups: (1) dark-green and deep-yellow vegetables and fruits (green salad, kale, broccoli, spinach, pumpkin, carrot, sweet potatoes, papaya and mango); (2) total fruit and fruit juices (orange, papaya, banana, apple, pear, watermelon, melon, grape, pineapple, avocado, mango, persimmon, orange juice and fruit juices); (3) only citrus fruit and citrus fruit juices (orange); (4) total vegetables (lettuce, chicory, watercress, cabbage, Chinese cabbage, cauliflower, kale, broccoli, spinach, pumpkin, sweet potatoes, carrot, tomato, aubergine, peas, beans, green been, beetroot, summer squash, mixed vegetables and vegetable soup); (5) total fruit and vegetables (vegetables and fruits reported earlier).

\section{Serum micronutrient analyses}

All participants were scheduled to provide a fasting blood sample within 1 week after recruitment in the study. Whole blood was collected, protected from light, centrifuged within $1 \mathrm{~h}$ of collection and frozen at $-70^{\circ} \mathrm{C}$ until being analysed. Serum samples were analysed for total carotene $(\beta-, \alpha$ - and $\gamma$-carotene), lycopene, $\alpha$ - and $\gamma$-tocopherols and retinol by HPLC (HP-1100 HPLC system; Hewlett Packard, Palo Alto, CA, USA), as described elsewhere ${ }^{(36)}$. Peaks for carotenoids that were under the quantification limits were set to zero. There were two samples for total carotene (one control and one diagnosed with CIN3), and one sample for lycopene (diagnosed with CIN3) that were below the limit of quantification (the detectable level of total carotene, lycopene and $\gamma$-tocopherol were 0.5 , $0 \cdot 2$ and $0.2 \mu \mathrm{mol} / 1$, respectively). Serum total cholesterol was measured enzymatically using an automatic device (ADVIA 1650; Bayer, East Walpole, MA, USA). All samples were analysed within 6 months after collection.
The laboratory assayed internal and external blinded quality-control specimens in every run. From the control specimens, the accuracy and inter-assay $\mathrm{CV}$ for these analytes were within $8 \%$.

\section{Human papillomavirus testing}

Exfoliated cervical cells were collected from each woman using the DNA-Cytoliq ${ }^{\circledR}$ (Digene Brazil, São Paulo, Brazil) liquid-based system. The ectocervical and endocervical samples were collected using the brush provided with the kits and immersed in Universal Collecting Medium ${ }^{\mathrm{TM}}$ vials. The cervical specimen was stored at $4{ }^{\circ} \mathrm{C}$ until processing for cytology and HPV testing.

Laboratory personnel were blinded to the case-control status of the participants. The cervical specimens were centrifuged at $5000 \mathrm{rpm}$ for $10 \mathrm{~min}$ at $22-24^{\circ} \mathrm{C}$. Cells were digested with $0.2 \mathrm{mg} / \mathrm{ml}$ proteinase $\mathrm{K}$ in $50 \mu \mathrm{l} 100 \mathrm{~mm}$ $\mathrm{NaCl}, 10 \mathrm{~mm}$-Tris-HCl (pH 8.0), 25 mm-EDTA buffer $(\mathrm{pH}$ $8 \cdot 0$ ), $0.5 \%$ SDS between 2 and $16 \mathrm{~h}$ at $60^{\circ} \mathrm{C}$ and purified. Extracted DNA was tested for the presence of human DNA using a PCR protocol for $\beta$-globin and for HPV DNA by a PCR protocol amplifying a highly conserved 450 bp segment in the $L 1$ viral gene (flanked by primers MY09/11), as described previously ${ }^{(22)}$. Typing of amplified products was performed by hybridisation with individual oligonucleotide probes specific for twenty-seven HPV genital types 6, 11, 16, 18, 26, 31, 33, 35, 39, 40, 42, 44, 45, 51, 52, 53, 54, 56, 57, 58, 59, 66, 68, 73, 82, 83 and 84 .

HPV types were classified as having either high-risk oncogenic potential or low-risk oncogenic potential. The high-risk types included HPV 16, 18, 31, 33, 35, 39, 45, 51, 52, 56, 58, 59, 68, 73 and $82^{(37)}$. HPV infection status was classified as per the following four hierarchical mutually exclusive categories: (1) HPV negative; (2) only positive for low-risk HPV types; (3) positive for at least one high-risk HPV type except HPV-16 and HPV-18; (4) positive for HPV-16 and/or HPV-18.

\section{Statistical analysis}

The Pearson $\chi^{2}$ test was used to examine differences in proportions between the CIN3 and control groups stratified by smoking habit (non-smoker or former and current smoker). Median values and interquartile ranges were calculated for serum micronutrients and dietary intakes according to the outcome status. The Mann-Whitney test was used for comparison between groups for continuous variables.

Serum tocopherols were adjusted for serum total cholesterol $^{(38)}$ and classified according to the nutritional adequacy of $\alpha$-tocopherol (normal values $\geq 2.5 \mu \mathrm{mol}$ / mmol $v$. inadequacy $)^{(39)}$. Serum retinol concentrations were dichotomised according to adequacy $(\geq 1.50$ $v . \leq 1.49 \mu \mathrm{mol} / \mathrm{l})$, serum lycopene and total carotene were categorised according to a cut-off point of the 
median concentrations of 0.41 and $0.28 \mu \mathrm{mol} / 1$ (below $v$. above the median concentration), respectively ${ }^{(40)}$, measured in the National Health and Nutrition Examination Survey III among healthy non-smoker women. Serum $\boldsymbol{\gamma}$-tocopherol adjusted for serum total cholesterol was categorised according to a cut-off point of the median concentration of $1.03 \mu \mathrm{mol} / \mathrm{mmol}$ (below $v$. above the median concentration) observed in the National Health and Nutrition Examination Survey 1999-2000 among the healthy non-institutionalised US population ${ }^{(41)}$. Vegetable and fruit intakes were dichotomised (below $v$. above daily intake of one portion of fruits or half portion of vegetables) based on the daily intake of $80 \mathrm{~g}$ total fruit and fruit juices, $80 \mathrm{~g}$ total citrus fruits and citrus fruit juices, $40 \mathrm{~g}$ total vegetables, $40 \mathrm{~g}$ dark-green and deep-yellow vegetables and fruits and $320 \mathrm{~g}$ or four portions of total vegetable and fruit group intakes. Unconditional logistic regression models were used to calculate OR for CIN3 according to combinations of tobacco smoking status and dietary or nutritional variables, with individuals in the first category of the exposure of interest as the reference group.

To assess interaction, all participants were categorised in four groups stratified by tobacco smoking status (nonsmokers $v$. former and current smokers) and dietary intakes or serum micronutrients (same categories reported earlier ${ }^{(42,43)}$. Former and current smokers were combined due to similarity in the micronutrients concentrations and fruit and vegetable intake ${ }^{(30)}$. All analyses were adjusted for age (21-30, 31-40, 41-50 and 51-65 years), hospital (Instituto Brasileiro de Controle do Câncer and Hospital Perola Byington), race/ethnicity (white and non-white), schooling ( $\geq 6$ and $\leq 5$ years) and potential confounders or mediators if their inclusion in any of the models caused a change in the OR estimate of $10 \%$ or more: sexual debut ( $\geq 20,17-19$ and $\leq 16$ years), lifetime sexual partner (1, 2 and $\geq 3$ partners), parity (0,1-3 and $\geq 4$ pregnancies) and HPV status (as defined above). A restricted analysis was performed selecting only women infected with high-risk HPV types.

Interaction was identified by comparing the observed OR for the joint effect of smoking and dietary intake and the expected OR using a simple mathematical operation $^{(43)}$. The Wald test and likelihood ratio test were used to test for the statistical significance of the estimated interaction term $^{(44,45)}$. In the likelihood ratio test, the difference of log-likelihood statistics for two models, one model with and the other model without interaction terms, and in the Wald test only one parameter, the interaction term, were tested. In the adjusted model, effect modification was assessed by including the interaction terms between the two variables of interest (tobacco smoking status and dietary intake or serum micronutrients, for example: $40 \mathrm{~g}$ vegetables $\times$ smoking status) ${ }^{(44)}$. Additional analyses were conducted with six categorical variables considering three tobacco smoking status (non-smoker, former smoker, current smoker) and dietary intakes and serum micronutrients.
Statistical significance was set at 0.05, and 95\% CI around the $\mathrm{OR}$ are presented. All $P$ values were derived from two-sided statistical tests. All analyses were done in STATA 9.0 (StataCorp, College Station, TX, USA).

\section{Results}

The study population reported a low intake of fruits and vegetables (median intake about $250 \mathrm{~g} / \mathrm{d}$ ) far below the WHO recommendation of $400 \mathrm{~g} / \mathrm{d}$ for this food group ${ }^{(23)}$. The primary reported fruits and vegetables were orange, banana, kale and tomato available during all seasons in São Paulo. Median values of fruit and fruit juices were 144 (interquartile range 61-299) and 99 (interquartile range $62-150) \mathrm{g} / \mathrm{d}$ of total vegetables. Significantly reduced consumption of vegetables and fruit groups and serum micronutrient concentrations were observed among the CIN3 cases when compared with those among the controls $(P<0.005)$. Former and current smokers reported a lower intake of fruits and serum total carotene, lycopene and tocopherols $(P<0.05)$ among both the controls and CIN3 cases (data not shown).

Table 1 shows the distribution of the CIN3 cases and the controls according to the selected covariates and stratified by smoking status according to selected covariates. Differences were observed between the cases and controls among former and current smokers: cases tended to be younger, non-white, less educated, on lower incomes and to have had an earlier sexual debut than the controls. However, lifetime number of sexual partners, higher parity and higher proportion of oncogenic type of HPV infection were observed among CIN3 women for both smoking status groups. Lower dietary intakes of vegetables and fruits and serum micronutrient concentrations were observed among the CIN3 cases than among the controls for both smoking status groups $(P<0 \cdot 05)$ (data not shown).

Table 2 shows the age- and hospital-adjusted OR for CIN3 by dietary intake and serum micronutrients, overall and stratified according to tobacco smoking status. Estimated risks differed slightly among lifelong non-users of tobacco, and no consistent associations emerged, apart from the finding that increases in risk were invariably associated with lower consumption or concentration categories. CI were wide, except for serum tocopherols. However, an increased risk of lower intake of dark-green and deep-yellow vegetables and fruits and lower concentration of serum $\alpha$-tocopherol was identified among former and current smokers.

Table 3 presents the adjusted joint effects of dietary intake and tobacco smoking on the risk of developing CIN3. The observed OR for the joint effect of smoking and intake of dark-green and deep-yellow vegetables and fruits (adjusted OR 3.86; 95\% CI 1.74, 8.57) was slightly greater than the expected $\mathrm{OR}$ in the additive model $(1.14+1.82-1.00=1.96)$, suggesting an interaction. A similar additive interaction was found between smoking 
Table 1. Characteristics of the study subjects stratified by smoking habit and outcome status $\dagger$ (Number of study subjects and percentages)

\begin{tabular}{|c|c|c|c|c|c|c|c|c|}
\hline & \multicolumn{4}{|c|}{ Non-smokers } & \multicolumn{4}{|c|}{ Former and current smokers } \\
\hline & \multicolumn{2}{|c|}{ CIN3 cases } & \multicolumn{2}{|c|}{ Control } & \multicolumn{2}{|c|}{ CIN3 cases } & \multicolumn{2}{|c|}{ Control } \\
\hline & $n$ & $\%$ & $n$ & $\%$ & $n$ & $\%$ & $n$ & $\%$ \\
\hline \multicolumn{9}{|l|}{ Age (years) } \\
\hline $21-30$ & 28 & $42 \cdot 4$ & 73 & $28 \cdot 0$ & 28 & $17 \cdot 0$ & 35 & $18 \cdot 2$ \\
\hline $31-40$ & 17 & $25 \cdot 8$ & 69 & $26 \cdot 4$ & 69 & $41 \cdot 8$ & 44 & 22.9 \\
\hline $41-50$ & 12 & $18 \cdot 2$ & 71 & $27 \cdot 2$ & 50 & $30 \cdot 3$ & 72 & 37.5 \\
\hline $51-65$ & 9 & 13.6 & 48 & 18.4 & $18^{*}$ & 10.9 & 41 & 21.4 \\
\hline \multicolumn{9}{|l|}{ Race/ethnicity } \\
\hline White & 17 & $25 \cdot 8$ & 98 & 37.5 & 37 & $22 \cdot 4$ & 78 & 40.6 \\
\hline Non-white & 49 & $74 \cdot 2$ & 163 & 62.5 & $128^{*}$ & 77.6 & 114 & 59.4 \\
\hline \multicolumn{9}{|l|}{ Years of schooling } \\
\hline$\geq 6$ & 36 & 54.5 & 172 & 65.9 & 71 & 43.0 & 116 & 60.4 \\
\hline$\leq 5$ & 30 & $45 \cdot 5$ & 89 & $34 \cdot 1$ & $94^{*}$ & $57 \cdot 0$ & 76 & 39.6 \\
\hline \multicolumn{9}{|l|}{ Income per person (USD/month) } \\
\hline$\geq 100$ & 18 & $28 \cdot 1$ & 80 & 30.9 & 24 & $14 \cdot 8$ & 70 & 36.6 \\
\hline $51-99$ & 20 & $31 \cdot 3$ & 96 & $37 \cdot 1$ & 49 & $30 \cdot 3$ & 54 & 28.3 \\
\hline$\leq 50$ & 26 & $40 \cdot 6$ & 83 & $32 \cdot 0$ & $89^{*}$ & 54.9 & 67 & $35 \cdot 1$ \\
\hline \multicolumn{9}{|l|}{ Age at first vaginal intercourse (years) } \\
\hline$\geq 20$ & 8 & $12 \cdot 1$ & 100 & $38 \cdot 3$ & 17 & $10 \cdot 4$ & 52 & $27 \cdot 1$ \\
\hline $17-19$ & 28 & $42 \cdot 4$ & 84 & $32 \cdot 2$ & 57 & 34.8 & 77 & $40 \cdot 1$ \\
\hline$\leq 16$ & 30 & $45 \cdot 5$ & 77 & 29.5 & $90^{*}$ & $54 \cdot 8$ & 63 & $32 \cdot 8$ \\
\hline \multicolumn{9}{|l|}{ Lifetime number of sexual partners } \\
\hline 1 & 15 & $22 \cdot 7$ & 123 & $47 \cdot 1$ & 24 & 14.6 & 68 & 35.6 \\
\hline 2 & 13 & $19 \cdot 7$ & 59 & $22 \cdot 6$ & 36 & $22 \cdot 0$ & 37 & $19 \cdot 4$ \\
\hline$\geq 3$ & $38^{*}$ & $57 \cdot 6$ & 79 & 30.3 & $104^{*}$ & 63.4 & 86 & $45 \cdot 0$ \\
\hline \multicolumn{9}{|l|}{ Number of pregnancies } \\
\hline 0 & 3 & 4.5 & 35 & 13.4 & 24 & 14.6 & 68 & 35.6 \\
\hline $1-3$ & 35 & $53 \cdot 0$ & 171 & 65.5 & 82 & $50 \cdot 0$ & 83 & 43.5 \\
\hline$\geq 4$ & $28^{*}$ & $42 \cdot 4$ & 55 & $21 \cdot 1$ & $58^{*}$ & $35 \cdot 4$ & 40 & $20 \cdot 9$ \\
\hline \multicolumn{9}{|l|}{ Oral contraceptive use } \\
\hline Never & 19 & $28 \cdot 8$ & 67 & $25 \cdot 7$ & 41 & $24 \cdot 8$ & 45 & 23.4 \\
\hline Former & 28 & $42 \cdot 4$ & 142 & 54.4 & 91 & $55 \cdot 2$ & 119 & $62 \cdot 0$ \\
\hline Current & 19 & $28 \cdot 8$ & 52 & $19 \cdot 9$ & 33 & $20 \cdot 0$ & 28 & $14 \cdot 6$ \\
\hline \multicolumn{9}{|l|}{ HPV status } \\
\hline HPV negative & 2 & $3 \cdot 0$ & 185 & $70 \cdot 9$ & 13 & $7 \cdot 9$ & 139 & $72 \cdot 4$ \\
\hline Positive only for low-risk HPV & 0 & 0 & 17 & 6.5 & 3 & 1.8 & 7 & 3.6 \\
\hline Positive for at least one high-risk type except HPV-16/HPV-18 & 19 & $28 \cdot 8$ & 21 & 8.0 & 33 & $20 \cdot 0$ & 24 & 12.5 \\
\hline Positive for HPV-16 and/or HPV-18 & $45^{*}$ & $68 \cdot 2$ & 38 & $14 \cdot 6$ & $116^{*}$ & $70 \cdot 3$ & 22 & 11.5 \\
\hline
\end{tabular}

CIN3, cervical intraepithelial neoplasia grade 3; USD, US dollar; HPV, human papillomavirus.

* Proportions were significantly different from those of the control group ( $\chi^{2}$ test): $P \leq 0.001$.

† Totals do not coincide due to missing values for some variables.

status and total fruit and fruit juice intake. However, the expected joint OR for total citrus fruit and citrus fruit juices and total vegetables were fairly close to the observed OR, so interaction if any was weak. The additive modification effect observed in fruit intake and smoking was not observed for total vegetable and fruit intake. Compared with never-exposed women, joint exposure to lower consumption of dark-green and deep-yellow vegetables and fruits, total fruit and fruit juices yielded about a fourfold risk for CIN3 after adjusting for confounding variables and HPV status. A strong and significant dose-response relationship was observed, although the interaction term was not statistically significant under any of the models.

With regard to the joint effect of serum micronutrients and smoking habits (Table 4), although the interaction was not statistically significant, our data suggest that adequate concentrations of $\alpha$-tocopherol carried a lower risk (adjusted OR 2.73; 95\% CI 1.26, 5.92) than in women with a deficiency (adjusted OR 5.86; 95\% CI 2.30, 14.96) among former and current smokers. A similar effect was observed for high concentrations of serum total carotene and $\gamma$-tocopherol.

An additional analysis of the joint effects of dietary intakes and smoking was conducted only among women positive for high-risk HPV infection. A lower intake of dark-green and deep-yellow vegetables and fruits without tobacco smoking had a small effect on CIN3 individuals (OR 1.16; 95\% CI $0 \cdot 47,2 \cdot 85$ ) than among smokers with higher intake (OR 2.14; $95 \%$ CI 0.77, 5.91). Joint exposure of tobacco smoking and lower intake was OR 2.73 (95\% CI $1 \cdot 16,6.38$ ), after adjusting for confounding variables, although the interaction term was not statistically significant. Infection with oncogenic HPV types is a prerequisite for cervical cancer, and our data suggest that a diet poor in fruits and vegetables, especially in dark-green and deepyellow types, among smokers increases the risk for CIN3 
Table 2. Cervical intraepithelial neoplasia grade $3(\mathrm{CIN} 3)$ by daily dietary intake and serum micronutrient concentrations stratified by tobacco smoking status (Odds ratios and $95 \%$ confidence intervals)

\begin{tabular}{|c|c|c|c|c|c|c|c|c|c|}
\hline Variable & \multicolumn{3}{|c|}{ All } & \multicolumn{3}{|c|}{ Non-smokers } & \multicolumn{3}{|c|}{ Former and current smokers } \\
\hline \multicolumn{10}{|c|}{ Dark-green and deep-yellow vegetables/fruits ( $\mathrm{g} / \mathrm{d}$ ) } \\
\hline$\leq 39$ & $178 / 285$ & 1.71 & $1 \cdot 15,2 \cdot 52$ & $47 / 162$ & $1 \cdot 11$ & $0.58,2 \cdot 12$ & $131 / 123$ & 1.96 & $1 \cdot 15,3.33$ \\
\hline \multicolumn{10}{|c|}{ Total fruit and fruit juices $(\mathrm{g} / \mathrm{d})$} \\
\hline$\geq 80$ & $139 / 326$ & 1.00 & & $39 / 194$ & 1.00 & & $100 / 132$ & 1.00 & \\
\hline$\geq 80$ & $98 / 240$ & 1.00 & & $29 / 148$ & 1.00 & & $69 / 92$ & 1.00 & \\
\hline$\leq 79$ & $132 / 211$ & 1.44 & $1.02,2.03$ & $36 / 112$ & 1.31 & $0.73,2.35$ & $96 / 99$ & 1.42 & $0.89,2.27$ \\
\hline \multicolumn{10}{|c|}{ Total vegetables $(\mathrm{g} / \mathrm{d})$} \\
\hline$\geq 40$ & $201 / 412$ & 1.00 & & $58 / 233$ & 1.00 & & $143 / 179$ & 1.00 & \\
\hline$\leq 39$ & 29/39 & 1.29 & $0.74,2.25$ & $7 / 27$ & 1.02 & $0.40,2.57$ & $22 / 12$ & 1.66 & $0.74,3.74$ \\
\hline \multicolumn{10}{|c|}{ Total vegetables and fruits $(\mathrm{g} / \mathrm{d})$} \\
\hline$\geq 320$ & $74 / 201$ & 1.00 & & $20 / 125$ & 1.00 & & $54 / 76$ & 1.00 & \\
\hline$\geq 0.41$ & $139 / 285$ & 1.00 & & $43 / 179$ & 1.00 & & $96 / 106$ & 1.00 & \\
\hline$\leq 0.40$ & $46 / 46$ & 1.88 & $1.14,3.08$ & $13 / 25$ & 1.95 & $0.87,4.34$ & $33 / 21$ & 1.53 & $0.79,2.99$ \\
\hline \multicolumn{10}{|c|}{ Serum retinol $(\mu \mathrm{mol} / \mathrm{l})$} \\
\hline$\geq 1.50$ & $113 / 232$ & 1.00 & & $36 / 153$ & 1.00 & & $77 / 79$ & 1.00 & \\
\hline$\leq 1.49$ & $72 / 99$ & 1.51 & $1 \cdot 00,2 \cdot 27$ & $20 / 51$ & 1.74 & $0.88,3.42$ & $52 / 48$ & $1 \cdot 18$ & $0.68,2.06$ \\
\hline \multicolumn{10}{|c|}{ Serum $\alpha$-tocopherol† $(\mu \mathrm{mol} / \mathrm{mmol})$} \\
\hline$\geq 2.50$ & $126 / 288$ & 1.00 & & $33 / 153$ & 1.00 & & $74 / 101$ & 1.00 & \\
\hline$\leq 2.49$ & $33 / 65$ & $2 \cdot 87$ & $1 \cdot 76,4.68$ & $23 / 48$ & $2 \cdot 72$ & $1 \cdot 28,5 \cdot 82$ & $55 / 25$ & 3.24 & $1.59,6.60$ \\
\hline \multicolumn{10}{|c|}{ Serum $\gamma$-tocopherol† $(\mu \mathrm{mol} / \mathrm{mmol})$} \\
\hline$\geq 1.03$ & $77 / 178$ & 1.00 & & $21 / 116$ & 1.00 & & $56 / 62$ & 1.00 & \\
\hline$\leq 1.02$ & $108 / 149$ & 1.51 & $1 \cdot 01,2 \cdot 24$ & $35 / 85$ & $2 \cdot 10$ & $1.09,4.04$ & $73 / 64$ & 1.22 & $0 \cdot 70,2 \cdot 11$ \\
\hline
\end{tabular}

* OR adjusted for age (21-30, 31-40, 41-50 and 51-65 years) and hospital (Instituto Brasileiro de Controle do Câncer and Hospital Perola Byington).

† Adjusted for serum total cholesterol.

about threefold compared with women who have a healthy diet and are not tobacco users. When we conducted an analysis restricted to women with oncogenic HPV infection for serum micronutrients, we observed an additive interaction effect of the low concentration of serum total carotene (OR 9.28; $95 \%$ CI 1.83, 46.96; $P$ for interaction $=0.64)$, retinol (OR 6.60; 95\% CI 2.31, 18.85; $P$ for interaction $=0.99)$ and $\gamma$-tocopherol and smoking habits (OR 4.28; $95 \%$ CI 1.55, 11.80; $P$ for interaction $=0.31)$ on the risk of CIN3. Additional interaction was not observed for other serum micronutrients.

We conducted an analysis investigating the joint effect of dietary intake and tobacco smoking in three categories (non-smoker, former smoker and current smoker) on the risk of CIN3. Considering non-smokers with higher intake as the reference category, former smokers presented intermediary risk followed by smokers with low and high intake for all investigated food groups and blood nutrients (data not shown).

\section{Discussion}

To our knowledge, this is the first study that focused on the effect of smoking on CIN3 as modified by diet. It is worrying since cervical cancer is the most common in developing countries and data from the WHO World Health Survey, a large cross-sectional study conducted in seventy low and medium-income countries in 2002-3 (including Brazil), showed a high prevalence of low fruit and vegetable intake $(<400 \mathrm{~g} / \mathrm{d}$ ) by $78 \%$ (about $58 \%$ in Brazil), with the highest prevalence of low fruit and vegetable intake $(82 \%)$ in the poorest income quintile ${ }^{(1,46)}$.

Our findings suggest a synergistic interaction between tobacco smoking and dietary intake of fruits and vegetables, in particular dark-green and deep-yellow vegetables and fruits, total fruit and fruit juices. However, since we found no additive interaction for total vegetables and fruits, it is likely that the effect on CIN3 is associated with specific nutrients found particularly in dark-green and deep-yellow vegetables and fruits rich in $\beta$-carotene. These associations were confirmed by serum total carotene, considered a good biomarker for fruit and vegetable intake, and serum vitamin $\mathrm{E}$, a potent antioxidant ${ }^{(30,47,48)}$.

The present results were consistent with the findings of previous studies: three cohorts and four case-control studies that have reported the synergistic effect of low intake of total fruit, total vegetables, total $\beta$-carotene, as well as a study on low plasma carotenoids and smoking habit for many cancers (oral, head and neck, oesophageal, gastric, ovarian and cervical, bladder and colorectal 
Table 3. Combined effect of daily dietary intakes and tobacco smoking status on cervical intraepithelial neoplasia grade 3 (CIN3) risk (Odds ratios and $95 \%$ confidence intervals)

\begin{tabular}{|c|c|c|c|c|c|}
\hline $\begin{array}{l}\text { Food } \\
\text { groups }\end{array}$ & $\begin{array}{l}\text { Smoking } \\
\text { status }^{*}\end{array}$ & CIN3 & Control & OR† & $95 \% \mathrm{Cl}$ \\
\hline \multicolumn{6}{|c|}{ Dark-green and deep-yellow vegetables/fruits (g/d) } \\
\hline$\geq 40$ & Never & 18 & 98 & 1.00 & \\
\hline$\leq 39$ & Never & 47 & 162 & $1 \cdot 14$ & $0.49,2.65$ \\
\hline$\geq 40$ & Ever & 34 & 68 & $1 \cdot 83$ & $0.73,4.62$ \\
\hline$\leq 39$ & Ever & 131 & 123 & \multicolumn{2}{|c|}{$P$ for interaction $=0.30$} \\
\hline \multicolumn{6}{|c|}{ Total fruit and fruit juices (g/d) } \\
\hline$\geq 80$ & Never & 39 & 194 & $1 \cdot 00$ & \\
\hline$\leq 79$ & Never & 26 & 66 & 1.54 & $0.70,3.38$ \\
\hline$\geq 80$ & Ever & 100 & 132 & 3.03 & $1.63,5.64$ \\
\hline$\leq 79$ & Ever & 65 & 59 & \multicolumn{2}{|c|}{$P$ for interaction $=0.20$} \\
\hline \multicolumn{6}{|c|}{ Total citrus fruit and citrus fruit juices $(\mathrm{g} / \mathrm{d})$} \\
\hline$\geq 80$ & Never & 29 & 148 & 1.00 & \\
\hline$\leq 79$ & Never & 36 & 112 & $1 \cdot 40$ & $0.66,2.95$ \\
\hline$\geq 80$ & Ever & 69 & 92 & $3 \cdot 22$ & $1.57,6.58$ \\
\hline$\leq 79$ & Ever & 96 & 99 & \multicolumn{2}{|c|}{$P$ for interaction $=0.64$} \\
\hline \multicolumn{6}{|c|}{ Total vegetables (g/d) } \\
\hline$\geq 40$ & Never & 58 & 233 & $1 \cdot 00$ & \\
\hline$\leq 39$ & Never & 7 & 27 & $1 \cdot 19$ & $0.36,3.98$ \\
\hline$\geq 40$ & Ever & 143 & 179 & 2.91 & $1.71,4.96$ \\
\hline$\leq 39$ & Ever & 22 & 12 & \multicolumn{2}{|c|}{$P$ for interaction $=0.91$} \\
\hline \multicolumn{6}{|c|}{ Total vegetables and fruits $(\mathrm{g} / \mathrm{d})$} \\
\hline$\geq 320$ & Never & 20 & 125 & 1.00 & \\
\hline$\leq 319$ & Never & 45 & 135 & $6 \cdot 90$ & $3.01,15.82$ \\
\hline$\geq 320$ & Ever & 54 & 76 & $7 \cdot 00$ & $3 \cdot 20,15 \cdot 31$ \\
\hline$\leq 319$ & Ever & 111 & 115 & \multicolumn{2}{|c|}{$P$ for interaction $=0.20$} \\
\hline
\end{tabular}

${ }^{*}$ Ever smoker: former smoker and current smoker

† OR adjusted for age (21-30, 31-40, 41-50 and 51-65 years), hospital (Instituto Brasileiro de Controle do Câncer and Hospital Perola Byington), race/ethnicity (white and non-white), schooling ( $\geq 6$ and $\leq 5$ years), sexual debut ( $\geq 20,17-19$ and $\leq 16$ years), lifetime sexual partners $(1,2$ and $\geq 3$ partners), parity $(0,1-3$ and $\geq 4$ pregnancies), human papillomavirus (HPV) status (negative for HPV, positive only for low-risk HPV, positive for at least one high-risk type except HPV-16/HPV-18 and positive for HPV-16 and/or HPV-18).

adenoma) that ranged from a $50 \%$ greater risk to a thirteenfold risk ${ }^{(49-55)}$. All these studies showed statistically non-significant results for the interaction term, except for the study investigating blood $\beta$-carotene ${ }^{(51)}$.

As suggested by Szklo \& Nieto ${ }^{(43)}$, interaction can be assessed by the comparison of an observed risk and their expected joint effects. Many discussions about concepts of interaction have been conducted in the previous decades based on statistical interaction, biological, public health and individual decision-making ${ }^{(42)}$. For public health interest, the proportion of the population at risk according to the exposed variable and risk with both exposures is important to inform policy regardless of statistical significance for judging whether two variables are synergistic ${ }^{(42,56)}$. Although precision of the estimated risk was affected by reduced sample size in some categories, the highest risk for CIN3 among smoking women who reported lower intake of fruits and vegetables is sufficient to suggest that CIN3 is modified by nutritional factors.

Many possible explanations for the biological plausibility of intake of fruits and vegetables, rich in $\beta$-carotene, associated with cancer have been reported: (1) antioxidant activity that mitigates the damaging effects of endogenous and exogenous ROS on cellular membranes, protein and nucleic acids; (2) conversion to vitamin A; (3) gap junction communication; (4) immunological function since carotenoids are important to maintain membrane receptors; (5) cell growth regulation; (6) modulation of gene expression; (7) regeneration of oxidised vitamin $\mathrm{E}$ important for the protection of lipids in membranes ${ }^{(24,57-62)}$. It is important to remember that smoking is one of the causes of ROS. In our previous analysis conducted in the total study population, lower intake of fruit and fruit juices and reduced total carotene concentrations independent of dietary intake were observed among smokers ${ }^{(30)}$. A significant linear trend between serum total carotene and quartiles of total fruit and fruit juices and quartiles of dark-green and deep-yellow vegetables and fruits was observed for non-smokers and smokers $(P \text { for trend }<0 \cdot 001)^{(30)}$. A possible explanation would be the enhanced turnover rate in response to the oxidant load ${ }^{(25-28,62)}$.

Table 4. Combined effect of serum micronutrients and tobacco smoking status on cervical intraepithelial neoplasia grade 3 (CIN3) risk

(Odds ratios and $95 \%$ confidence intervals)

\begin{tabular}{|c|c|c|c|c|c|}
\hline $\begin{array}{l}\text { Serum } \\
\text { micronutrients }\end{array}$ & $\begin{array}{l}\text { Smoking } \\
\text { status* }\end{array}$ & CIN3 & Control & OR† & $95 \% \mathrm{Cl}$ \\
\hline \multicolumn{6}{|c|}{ Total carotene $(\mu \mathrm{mol} / \mathrm{l})$} \\
\hline$\geq 0.28$ & Never & 46 & 186 & 1.00 & \\
\hline$\leq 0.27$ & Never & 10 & 18 & 1.47 & $0.47-4.62$ \\
\hline$\geq 0.28$ & Ever & 99 & 109 & 3.40 & $1.76-6.58$ \\
\hline$\leq 0.27$ & Ever & 30 & 18 & $\begin{array}{c}4.57 \\
P \text { for in }\end{array}$ & $\begin{array}{c}1.56-13.39 \\
\text { action }=0.91\end{array}$ \\
\hline \multicolumn{6}{|c|}{ Lycopene ( $\mu \mathrm{mol} / \mathrm{l})$} \\
\hline$\geq 0.41$ & Never & 43 & 179 & 1.00 & \\
\hline$\leq 0.40$ & Never & 13 & 25 & $2 \cdot 37$ & $0.81-6.95$ \\
\hline$\geq 0.41$ & Ever & 96 & 106 & 4.18 & $2 \cdot 11-8.29$ \\
\hline$\leq 0.40$ & Ever & 33 & 21 & \multicolumn{2}{|c|}{$P$ for interaction $=0.14$} \\
\hline \multicolumn{6}{|l|}{ Retinol $(\mu \mathrm{mol} / \mathrm{l})$} \\
\hline$\geq 1.50$ & Never & 36 & 153 & 1.00 & \\
\hline$\leq 1.49$ & Never & 20 & 51 & 2.33 & $0.93-5.82$ \\
\hline$\geq 1.50$ & Ever & 77 & 79 & 4.33 & $2 \cdot 02-9 \cdot 29$ \\
\hline$\leq 1.49$ & Ever & 52 & 48 & \multicolumn{2}{|c|}{$P$ for interaction $=0.19$} \\
\hline \multicolumn{6}{|c|}{$\alpha$-Tocopherol $\ddagger(\mu \mathrm{mol} / \mathrm{mmol})$} \\
\hline$\geq 2.50$ & Never & 33 & 153 & 1.00 & \\
\hline$\leq 2.49$ & Never & 23 & 48 & 1.14 & $0.47-2.76$ \\
\hline$\geq 2.50$ & Ever & 74 & 101 & 2.73 & $1.26-5.92$ \\
\hline$\leq 2.49$ & Ever & 55 & 25 & \multicolumn{2}{|c|}{$P$ for interaction $=0.33$} \\
\hline \multicolumn{6}{|c|}{$\gamma$-Tocopherol $(\mu \mathrm{mol} / \mathrm{mmol})$} \\
\hline$\geq 1.03$ & Never & 21 & 116 & 1.00 & \\
\hline$\leq 1.02$ & Never & 35 & 85 & 1.53 & $0.64-3.65$ \\
\hline$\geq 1.03$ & Ever & 56 & 62 & 3.42 & $1.36-8.58$ \\
\hline$\leq 1.02$ & Ever & 73 & 64 & \multicolumn{2}{|c|}{$P$ for interaction $=0.96$} \\
\hline
\end{tabular}

* Ever smoker: former smoker and current smoker.

† OR adjusted for age (21-30, 31-40, 41-50 and 51-65 years), hospital (Instituto Brasileiro de Controle do Câncer and Hospital Perola Byington), race/ethnicity (white and non-white), schooling ( $\geq 6$ and $\leq 5$ years), sexual debut ( $\geq 20,17-19$ and $\leq 16$ years), lifetime sexual partners $(1,2$ and $\geq 3$ partners), parity $(0,1-3$ and $\geq 4$ pregnancies), human papillomavirus (HPV) status (negative for HPV, positive only for low-risk HPV, positive for at least one high-risk type except HPV-16/HPV-18 and positive for HPV-16 and/or HPV-18).

$\ddagger$ Adjusted for serum total cholesterol. 
Vitamin E or $\alpha$-tocopherol, the major compound with highest biological activity, is considered to be the major lipid-soluble antioxidant present in cellular membranes ${ }^{(63)}$. The anti-carcinogenic activity of $\alpha$-tocopherol is to reduce ROS damage of DNA and avoid oxidation of immunological cellular membranes rich in fatty acids ${ }^{(64)}$. Changes in fatty acid composition of immune cell membranes showed an effect on fluidity of the membrane, distribution and function of cellular receptors, and changed the affinity of immune cell, thus reducing the immunological response ${ }^{(64)}$. In previous studies, serum $\alpha$-tocopherol concentrations in smokers compared with non-smokers have been controversial ${ }^{(65-68)}$. Previous research on serum $\gamma$-tocopherol has showed slightly increased concentrations among smokers ${ }^{(26,66)}$; however, further studies are necessary to identify differential metabolism of tocopherols and activity of other forms of vitamin $\mathrm{E}$ in the body.

Several limitations of the present study should be noted. First, the design of the study is prone to selection and recall bias, while residual influences of dietary intakes could have distorted the findings. However, the participation rate in the main study was very high, 97\% (thirty-four potential cases and nineteen potential controls refused), thereby minimising the selection bias. Recall bias is another weakness of case-control studies. Regarding this possible limitation, subject recruitment and interviews were conducted before diagnosis. The FFQ used reflects the usual intake over a previous year, and the biomarker for fruit and vegetable intake is sensitive for recent intakes. Although biochemical indicators can be considered an objective measure of exposure when compared with dietary intake reports, they are also prone to misclassification due to within-person variability and can result in random error that can attenuate estimates of association ${ }^{(69)}$. A similar magnitude of the effect on CIN3 was also observed on fruit and vegetable intake and on the best biomarker for fruit consumption (total carotene), reflecting that longtime and recent exposures were associated with CIN3. Second, the findings of the present study are prone to residual confounding by sexual activity, strongly correlated with smoking habits. Although we used a sensitive method for HPV infection diagnosis, it is possible that some unmeasured factor associated with sexual behaviour could be present, thus distorting the results ${ }^{(70)}$. However, we tried to minimise the effect of residual confounding of sexual lifestyle by conducting an HPV-specific analysis only among high-risk HPV-positive women. This analysis confirmed the findings with the entire sample.

The present results suggest that there is an additive interaction of low intake of fruits and vegetables, especially dark-green and deep-yellow vegetables and fruits, and smoking habits on CIN3 risk. These results were confirmed using biomarkers of fruit intake and also from restricted analyses conducted among women infected by oncogenic HPV type. A higher risk of low intake of these food groups among smokers $v$. non-smokers may reflect the relative deficit of $\beta$-carotene intake, and thus a higher benefit achieved among smokers increasing its intake. These findings emphasise the public health importance of higher intake of vegetables and fruits, especially dark-green and deep-yellow vegetables and fruits, and, more importantly, of quitting smoking. Further studies on the interaction between dietary intake and smoking on HPV clearance are needed.

\section{Acknowledgements}

The present work was supported by research funding from Fundação de Amparo à Pesquisa do Estado de São Paulo, Brazil (FAPESP/03/03013-4) and Conselho Nacional de Desenvolvimento Científico e Tecnológico, Brazil (CNPq/ 473043/03-3, 300167/97-0). L. Y. T. received PhD scholarships from FAPESP (02/11184-0) and Coordenação de Aperfeiçoamento de Pessoal de Nível Superior (CAPES/ BEX3775/05-4). There are no conflicts of interest to declare. All authors made contributions to the study design and the interpretation of results. C. M. R.-M. and L. L. V. assisted in the development and implementation of the study protocols and contributed to the writing of the final manuscript. L. Y. T., E. L. F. and M. A. C. designed the overall study protocols, analysed the data and were responsible for the writing of the manuscript. All authors read and approved the final manuscript.

\section{References}

1. Parkin DM, Bray F, Ferlay J, et al. (2005) Global cancer statistics, 2002. CA Cancer J Clin 55, 74-108.

2. Kogevinas MPN, Susser M \& Boffetta P (1997) Social Inequalities and Cancer. Lyon: International Agency for Research on Cancer.

3. Parikh S, Brennan P \& Boffetta P (2003) Meta-analysis of social inequality and the risk of cervical cancer. Int $J$ Cancer 105, 687-691.

4. Walboomers JM, Jacobs MV, Manos MM, et al. (1999) Human papillomavirus is a necessary cause of invasive cervical cancer worldwide. J Pathol 189, 12-19.

5. Munoz N, Franceschi S, Bosetti C, et al. (2002) Role of parity and human papillomavirus in cervical cancer: the IARC multicentric case-control study. Lancet 359, 1093-1101.

6. Moreno V, Bosch FX, Munoz N, et al. (2002) Effect of oral contraceptives on risk of cervical cancer in women with human papillomavirus infection: the IARC multicentric case-control study. Lancet 359, 1085-1092.

7. Plummer M, Herrero R, Franceschi S, et al. (2003) Smoking and cervical cancer: pooled analysis of the IARC multi-centric case-control study. Cancer Causes Control 14, 805-814.

8. Appleby P, Beral V, Berrington de Gonzalez A, et al. (2006) Carcinoma of the cervix and tobacco smoking: collaborative reanalysis of individual data on 13,541 women with carcinoma of the cervix and 23,017 women without carcinoma of the cervix from 23 epidemiological studies. Int J Cancer 118, 1481-1495.

9. Vaccarella S, Herrero R, Snijders PJ, et al. (2008) Smoking and human papillomavirus infection: pooled analysis of the International Agency for Research on Cancer HPV Prevalence Surveys. Int J Epidemiol 37, 536-546. 
10. Poppe WA, Ide PS, Drijkoningen MPG, et al. (1995) Tobacco smoking impairs the local immunosurveillance in the uterine cervix. Gynecol Obstet Invest 39, 34-48.

11. Eiserich JP, van der Vliet A, Handelman GJ, et al. (1995) Dietary antioxidants and cigarette smoke-induced biomolecular damage: a complex interaction. Am J Clin Nutr 62 , Suppl. 6, S1490-S1500.

12. Goodman MT, Shvetsov YB, McDuffie K, et al. (2007) Hawaii cohort study of serum micronutrient concentrations and clearance of incident oncogenic human papillomavirus infection of the cervix. Cancer Res 67, 5987-5996.

13. Sedjo RL, Roe DJ, Abrahamsen M, et al. (2002) Vitamin A, carotenoids, and risk of persistent oncogenic human papillomavirus infection. Cancer Epidemiol Biomarkers Prev 11, 876-884.

14. Sedjo RL, Papenfuss MR, Craft NE, et al. (2003) Effect of plasma micronutrients on clearance of oncogenic human papillomavirus (HPV) infection (United States). Cancer Causes Control 14, 319-326.

15. Siegel EM, Craft NE, Duarte-Franco E, et al. (2007) Associations between serum carotenoids and tocopherols and type-specific HPV persistence: the Ludwig-McGill cohort study. Int J Cancer 120, 672-680.

16. Giuliano AR, Papenfuss M, Nour M, et al. (1997) Antioxidant nutrients: associations with persistent human papillomavirus infection. Cancer Epidemiol Biomarkers Prev 6, 917-923.

17. Giuliano AR, Siegel EM, Roe DJ, et al. (2003) Dietary intake and risk of persistent human papillomavirus (HPV) infection: the Ludwig-McGill HPV Natural History Study. J Infect Dis 188, 1508-1516.

18. Goodman MT, Kiviat N, McDuffie K, et al. (1998) The association of plasma micronutrients with the risk of cervical dysplasia in Hawaii. Cancer Epidemiol Biomarkers Prev 7, 537-544.

19. Schiff MA, Patterson RE, Baumgartner RN, et al. (2001) Serum carotenoids and risk of cervical intraepithelial neoplasia in Southwestern American Indian women. Cancer Epidemiol Biomarkers Prev 10, 1219-1222.

20. Nagata C, Shimizu H, Yoshikawa H, et al. (1999) Serum carotenoids and vitamins and risk of cervical dysplasia from a case-control study in Japan. Br J Cancer 81, $1234-1237$

21. Shannon J, Thomas DB, Ray RM, et al. (2002) Dietary risk factors for invasive and in situ cervical carcinomas in Bangkok, Thailand. Cancer Causes Control 13, 691-699.

22. Tomita LY, Logatto Filho A, Costa MC, et al. (2010) Diet and serum micronutrients in relation to cervical neoplasia and cancer among low-income Brazilian women. Int $J$ Cancer 126, 703-714.

23. World Cancer Research Fund/American Institute for Cancer Research (2007) Food, Nutrition, Physical Activity, and the Prevention of Cancer: A Global Perspective. Washington, DC: WCRF/AICR.

24. Chew BP \& Park JS (2004) Carotenoid action on the immune response. J Nutr 134, Suppl. 1, S257-S261.

25. Stryker WS, Kaplan LA, Stein EA, et al. (1988) The relation of diet, cigarette smoking, and alcohol consumption to plasma beta-carotene and alpha-tocopherol levels. Am J Epidemiol 127, 283-296

26. Dietrich M, Block G, Norkus EP, et al. (2003) Smoking and exposure to environmental tobacco smoke decrease some plasma antioxidants and increase gamma-tocopherol in vivo after adjustment for dietary antioxidant intakes. Am J Clin Nutr 77, 160-166.

27. Marangon K, Herbeth B, Lecomte E, et al. (1998) Diet, antioxidant status, and smoking habits in French men. Am J Clin Nutr 67, 231-239.
28. Galan P, Viteri FE, Bertrais S, et al. (2005) Serum concentrations of beta-carotene, vitamins $\mathrm{C}$ and $\mathrm{E}$, zinc and selenium are influenced by sex, age, diet, smoking status, alcohol consumption and corpulence in a general French adult population. Eur J Clin Nutr 59, 1181-1190.

29. Chow CK, Thacker RR, Changchit C, et al. (1986) Lower levels of vitamin $\mathrm{C}$ and carotenes in plasma of cigarette smokers. J Am Coll Nutr 5, 305-312.

30. Tomita LY, Almeira LC, Roteli-Martins CM, et al. (2009) Dietary predictors of serum total carotene in low-income women living in São Paulo, south-east Brazil. Public Health Nutr 12, $2133-2142$.

31. World Health Organization (2002) Diet, Nutrition and the Prevention of Chronic Diseases. Technical Report Series no. 916. Geneva: WHO.

32. Cardoso MA, Kida AA, Tomita LY, et al. (2001) Reproducibility and validity of a food frequency questionnaire among women of Japanese ancestry living in Brazil. Nutr Res 21, $725-733$.

33. Sartorelli DS, Sciarra EC, Franco LJ, et al. (2005) Beneficial effects of short-term nutritional counselling at the primary health-care level among Brazilian adults. Public Health Nutr 8, 820-825.

34. Cardoso MA, Tomita LY \& Laguna EC (2010) Assessing the validity of a food frequency questionnaire among lowincome women in São Paulo, southeastern Brazil. Cad Saúde Pública 26 (In the Press).

35. Block G, Coyle LM, Hartman AM, et al. (1994) Revision of dietary analysis software for the Health Habits and History Questionnaire. Am J Epidemiol 139, 1190-1196.

36. Gomes LF, Alves AF, Sevanian A, et al. (2004) Role of beta2glycoprotein I, LDL-, and antioxidant levels in hypercholesterolemic elderly subjects. Antioxid Redox Signal 6, $237-244$.

37. Munoz N, Bosch FX, de Sanjose S, et al. (2003) Epidemiologic classification of human papillomavirus types associated with cervical cancer. $N$ Engl J Med 348, 518-527.

38. Willett W (1988) Nutritional Epidemiology, 2nd ed. Oxford: Oxford University Press.

39. Haller J, Weggemans RM, Lammi-Keefe CJ, et al. (1996) Changes in the vitamin status of elderly Europeans: plasma vitamins A, E, B-6, B-12, folic acid and carotenoids. SENECA Investigators. Eur J Clin Nutr 50, Suppl. 2, S32-S46.

40. Wei W, Kim Y \& Boudreau N (2001) Association of smoking with serum and dietary levels of antioxidants in adults: NHANES III, 1988-1994. Am J Public Health 91, 258-264.

41. Ford ES, Schleicher RL, Mokdad AH, et al. (2006) Distribution of serum concentrations of alpha-tocopherol and gamma-tocopherol in the US population. Am J Clin Nutr 84, 375-383.

42. Rothman KJ, Greenland S \& Walker AM (1980) Concepts of interaction. Am J Epidemiol 112, 467-470.

43. Szklo M \& Nieto FJ (2000) Epidemiology Beyond the Basics. Boston, MA: Jones \& Bartlett Publishers.

44. Kleimbaum DG (1998) Logistic Regression: A Self-learning Text. New York: Springer-Verlag.

45. Knol MJ, van der Tweel I, Grobbee DE, et al. (2007) Estimating interaction on an additive scale between continuous determinants in a logistic regression model. Int J Epidemiol 36, 1111-1118

46. Hall JN, Spencer M, Harper SB, et al. (2009) Global variability in fruit and vegetable consumption. Am J Prev 36, 402-409.

47. Campbell DR, Gross MD, Martini MC, et al. (1994) Plasma carotenoids as biomarkers of vegetable and fruit intake. Cancer Epidemiol Biomarkers Prev 3, 493-500.

48. National Academy of Sciences, Institute of Medicine \& Food and Nutrition Board (2000) Dietary References Intake for 
Vitamin C, Vitamin E, Selenium, and Carotenoids: A Report of the Panel on Dietary Antioxidants and Related Compounds, Subcommittees on Upper Intakes, and the Standing Committee on the Scientific Evaluation of Dietary Reference Intakes, Food and Nutrition Board, Institute of Medicine. Washington, DC: National Academy Press.

49. Hansson LE, Baron J, Nyren O, et al. (1994) Tobacco, alcohol and the risk of gastric cancer. A population-based casecontrol study in Sweden. Int J Cancer 57, 26-31.

50. Senesse P, Touvier M, Kesse E, et al. (2005) Tobacco use and associations of beta-carotene and vitamin intakes with colorectal adenoma risk. J Nutr 135, 2468-2472.

51. Hung RJ, Zhang ZF, Rao JY, et al. (2006) Protective effects of plasma carotenoids on the risk of bladder cancer. J Urol 176, 1192-1197.

52. Maserejian NN, Giovannucci E, Rosner B, et al. (2006) Prospective study of fruit and vegetables and risk of oral premalignant lesions in men. Am J Epidemiol 164, 556-566.

53. Yamaji T, Inoue M, Sasazuki S, et al. (2008) Fruit and vegetable consumption and squamous cell carcinoma of the esophagus in Japan: the JPHC study. Int J Cancer 123, 1935-1940.

54. Kellen E, Zeegers M, Paulussen A, et al. (2006) Fruit consumption reduces the effect of smoking on bladder cancer risk. The Belgian case control study on bladder cancer. Int J Cancer 118, 2572-2578.

55. Boccia S, Cadoni G, Sayed-Tabatabaei FA, et al. (2008) CYP1A1, CYP2E1, GSTM1, GSTT1, EPHX1 exons 3 and 4, and NAT2 polymorphisms, smoking, consumption of alcohol and fruit and vegetables and risk of head and neck cancer. J Cancer Res Clin Oncol 134, 93-100.

56. de Gonzalez AM \& Cox DR (2007) Interpretation of interaction: a review. Ann Appl Stat 2, 371-385.

57. Bendich A \& Olson JA (1989) Biological actions of carotenoids. FASEB J 3, 1927-1932.

58. Zhang LX, Cooney RV \& Bertram JS (1991) Carotenoids enhance gap junctional communication and inhibit lipid peroxidation in $\mathrm{C} 3 \mathrm{H} / 10 \mathrm{~T} 1 / 2$ cells: relationship to their cancer chemopreventive action. Carcinogenesis 12, 2109-2114.
59. Bendich A (1989) Carotenoids and the immune response. J Nutr 119, 112-115.

60. Levy J, Bosin E, Feldman B, et al. (1995) Lycopene is a more potent inhibitor of human cancer cell proliferation than either alpha-carotene or beta-carotene. Nutr Cancer 24, $257-266$

61. Niki E, Noguchi N, Tsuchihashi H, et al. (1995) Interaction among vitamin $\mathrm{C}$, vitamin E, and beta-carotene. Am J Clin Nutr 62, Suppl. 6, S1322-S1326.

62. Ames BN \& Wakimoto P (2002) Are vitamin and mineral deficiencies a major cancer risk? Nat Rev Cancer 2, 694-704.

63. McCullough ML \& Giovannucci EL (2004) Diet and cancer prevention. Oncogene 23, 6349-6364.

64. Calder PC \& Grimble RF (2002) Polyunsaturated fatty acids, inflammation and immunity. Eur J Clin Nutr 56, Suppl. 3, S14-S19.

65. Marangon K, Herbeth B, Artur Y, et al. (1997) Low and very low density lipoprotein composition and resistance to copper-induced oxidation are not notably modified in smokers. Clin Chim Acta 265, 1-12.

66. Sobczak A, Golka D \& Szoltysek-Boldys I (2004) The effects of tobacco smoke on plasma alpha- and gamma-tocopherol levels in passive and active cigarette smokers. Toxicol Lett 151, 429-437.

67. Faure H, Preziosi P, Roussel AM, et al. (2006) Factors influencing blood concentration of retinol, alpha-tocopherol, vitamin $\mathrm{C}$, and beta-carotene in the French participants of the SU.VI.MAX trial. Eur J Clin Nutr 60, 706-717.

68. Hosomi A, Arita M, Sato Y, et al. (1997) Affinity for alphatocopherol transfer protein as a determinant of the biological activities of vitamin E analogs. FEBS Lett 409, 105-108.

69. Block G, Dietrich M, Norkus E, et al. (2006) Intraindividual variability of plasma antioxidants, markers of oxidative stress, C-reactive protein, cotinine, and other biomarkers. Am J Epidemiol 17, 404-412.

70. Franco EL \& Spence AR (2008) Commentary: smoking and human papillomavirus infection: the pursuit of credibility for an epidemiologic association. Int $J$ Epidemiol 37, $547-548$ 